\title{
¿PUEDE UN GERENTE SER UN LÍDER-COACH?
}

\author{
SILVIA GARCÍA VEGA \\ - Profesora de Indicadores y Control de Gestión de Capital Humano \\ Carrera de Administración y Recursos Humanos \\ Facultad de Negocios, UPC
}

\author{
SE HA DE PERCIBIR AL GERENTE COMO UN APOYO, \\ NO COMO UNA AMENAZA.

\section{J. WHITMORE}

En los últimos años, la palabra coaching se escucha cada vez más fuerte en el ámbito organizacional. Las empresas están dispuestas a invertir mucho dinero para contratar coaches que ayuden a "cambiar" a sus gerentes, con el fin de convertirlos en mejores jefes, capaces de superar los resultados esperados en cuanto a metas y en cuanto a personas. Sin embargo, un proceso de coaching no busca cambiar al otro mediante instrucciones de "cómo se deben hacer las cosas": el propósito es que el gerente descubra por sí mismo su potencial y el mundo de posibilidades que tiene a su alcance para lograr sus objetivos, apalancándose en sus fortalezas. Y que se dé cuenta de que una vez que lo haya logrado y se sienta satisfecho y realizado, llegará un nuevo reto, ya que será consciente de que la responsabilidad no es solo con él mismo, sino que todas sus acciones tienen un impacto en las personas de su entorno, y que a su vez él puede ser apoyo y guía para sus colaboradores en sus propios procesos de mejora continua.

Es por ello que, si uno desarrolla sus habilidades de lídercoach, uno estará, tanto en la capacidad de impactar positivamente en las personas que conforman su equipo de trabajo, como de generar compromiso, bienestar y un mejor desempeño individual y grupal, lo que indudablemente facilitará el cambio personal y organizacional. Ser un buen líder-coach significa ser coherente en todo sentido y vivir de acuerdo con tus valores, toda vez que es un proceso en el que uno ofrece orientación, apoyo y estímulo de manera individualizada a cada miembro del equipo. Sumado a ello, y en consonancia con lo señalado por J. Whitmore, autor de diversos libros sobre coaching y liderazgo, este proceso implica romper paradigmas sobre el concepto tradicional de "ser jefe", según el cual los gerentes están tan ocupados apagando incendios y resolviendo los problemas del día a día que queda poco tiempo para planificar y mucho menos para dedicarlo al desarrollo de sus colaboradores. En este contexto, dar órdenes es más rápido, aunque no siempre se obtengan los resultados deseados; pero, si uno decide invertir tiempo en poner en práctica sus habilidades como líder-coach, uno estará desarrollando las capacidades de los miembros del equipo. Como consecuencia, ellos crecerán y podrán asumir muchas más responsabilidades, además de que liberarán al gerente de la función de apagafuegos.

Por otro lado, ser un líder-coach involucra estimular diversas competencias, como valorar a las personas sobre la organización, con ética y valores y sin dejar de lado los indicadores de resultado; fomentar una comunicación abierta y la escucha activa; apreciar y promover el trabajo en equipo; aceptar la ambigüedad y la diversidad; y ser un facilitador para el desarrollo de los demás. Es una nueva y gratificante manera de gestionar, en la cual el primer paso es generar confianza con las personas que conforman el equipo de trabajo, tomando en cuenta que la confianza es una relación de doble vía, que se construye no solo cuando uno la brinda, sino también cuando la recibe.

¿Qué significa confianza? Según el diccionario Oxford online, confianza es la "esperanza firme que una persona tiene en que algo suceda, sea o funcione de una forma determinada, o en que otra persona actúe como ella desea". La esperanza (futuro: yo espero) firme (con determinación) es confiar en que esa apertura que uno esté brindando al otro sea retribuida de la misma manera. Por eso, cuando interactuamos con otro y confiamos en él o en ella, es porque apostamos que a futuro lo que pueda brindarnos será positivo para nosotros.

Cuando un colaborador está dispuesto a depositar su confianza en su jefe, es porque confía de manera plena en sus capacidades y ello hace que esté dispuesto a arriesgar. La relación de confianza entre el jefe y el colaborador se construye desde la primera conversación. Es indispensable que se le haga saber de manera clara al colaborador que él o ella puede esperar de su jefe una relación de trabajo abierta, honesta y de apoyo, que lo ayude a sacar lo mejor de sí mismo, comprometiéndose ambos con los resultados, importantes para cada uno, para el equipo, el área y la organización. De igual modo, crear un clima de confianza implica que, como jefe, uno mire a cada miembro de su equipo con esa misma confianza: confianza en sus fortalezas, confianza en sus capacidades, confianza en su potencial.

De la mano de la confianza, el líder-coach acompaña al colaborador en este proceso de autodescubrimiento con presencia plena, apertura y compromiso. Por lo tanto, en una relación de trabajo positiva, la confianza se construye, la expectativa se cumple, el corazón se abre y los resultados se alcanzan. 